\title{
La centralización de la gobernanza territorial en las políticas activas del mercado de trabajo en España durante la Gran Recesión (2011-2016)
}

\section{The centralization of territorial governance of active labor market policies in Spain during the Great Recession (2011-2016)}

\author{
Jorge José Hernández-Moreno \\ Instituto de Políticas y Bienes Públicos (IPP-CSIC) \\ jorgejose.hernandez-moreno@cchs.csic.es \\ Juan Antonio Ramos Gallarín \\ Universidad Rey Juan Carlos (URJC) \\ juan.ramos@urjc.es
}

\section{RESUMEN}

España ha sido uno de los países de Europa Occidental que más ha avanzado en el proceso de descentralización del Estado de Bienestar. Las décadas de los años 1990 y 2000 fueron testigo de una aceleración de este proceso, que ha ido acompañado de una expansión del gasto social a nivel subnacional, especialmente por parte de las Comunidades Autónomas (CC.AA). El presente artículo pretende contribuir a distintos debates abiertos acerca de los cambios en la dimensión territorial de la gobernanza en las políticas sociales y sus factores explicativos. En concreto, se centra en las políticas activas del mercado de trabajo (PAMT), tratando de responder a la cuestión de si las reformas introducidas en materia de activación en el Estado de Bienestar español en el contexto de la crisis han afectado al ejercicio de la autoridad y la responsabilidad política, financiera y administrativa de los diferentes niveles de gobierno.

\section{PALABRAS CLAVE}

Gobernanza territorial, políticas activas del mercado de trabajo, centralización, políticas sociales, empleo.

\begin{abstract}
Spain is among the West European countries that has achieved higher levels of decentralization in its Welfare State. The 1990s and 2000s witnessed an acceleration of this process, which has been accompanied by an expansion of social spending at the subnational level, especially by the Autonomous Communities (Autonomous Communities). This article aims to contribute to several debates regarding changes in the territorial dimension of governance in social policies and their explanatory factors. Specifically, it focuses on active labor market policies (ALMPs) and addresses the question of whether the reforms introduced in the field of activation in the context of the economic crisis have affected the exercise of political, financial and administrative authority by the different levels of government.
\end{abstract}

\section{KEYWORDS}

Territorial governance, active labour-market policies, centralization, social policies, employment.

\section{SUMARIO}

I. INTRODUCCIÓN. II. REVISIÓN DE LA LITERATURA, HIPÓTESIS DE INVESTIGACIÓN Y MARCO ANALÍTICO. III. LAS TRANSFORMACIONES DE LA GOBERNANZA TERRITORIAL EN LAS POLÍTICAS 
ACTIVAS DEL MERCADO DE TRABAJO EN ESPAÑA. 1. ANTECEDENTES. Decisión. Financiación. Implementación. 2. LOS CAMBIOS ACAECIDOS EN EL MARCO DE LA GRAN RECESIÓN. Decisión. Financiación. Implementación. IV. FACTORES EXPLICATIVOS DEL NUEVO MODELO DE GOBERNANZA TERRITORIAL DE LAACTIVACIÓN. 1. EL CONTEXTO SOCIO-ECONÓMICO. 2. EL PAPEL DE LA IDEOLOGÍA. 3. EL CONTEXTO POLÍTICO/INSTITUCIONAL. 4. CONDICIONANTES SUPRANACIONALES: LA PERTENENCIA A LA UE. V. CONCLUSIONES. VI. REFERENCIAS BIBLIOGRÁFICAS. VII. NOTA METODOLÓGICA.

\section{INTRODUCCIÓN ${ }^{1}$}

Mientras en la mayor parte de los Estados de Bienestar las políticas pasivas del mercado de trabajo (PPMT), consistentes básicamente en prestaciones, continúan siendo una competencia del Estado central, en las últimas cuatro décadas las políticas activas del mercado de trabajo (PAMT) han experimentado un fuerte proceso de descentralización (Bonoli, 2010; Graziano, 2012). Las PAMT incluyen cuatro grandes grupos de iniciativas: formación de los trabajadores, incentivos para la contratación y el mantenimiento del empleo, programas directos de empleo del sector público y, por último, servicios de orientación y seguimiento para mejorar los resultados de la búsqueda de empleo (de la Rica, 2015: 4-5). Los gobiernos regionales y locales, más cercanos al territorio y con mayor conocimiento de las peculiaridades del mercado de trabajo local a este nivel, desempeñan papeles relevantes en materia de gestión, diseño y financiación de dichas iniciativas (López-Santana, 2015, 2016; López-Santana y Moyer, 2012).

Esta investigación pretende contribuir a varios debates abiertos acerca de los cambios en la gobernanza de las políticas sociales en su dimensión territorial -en relación al continuo descentralización/centralización-, así como sobre los factores que los explican. En concreto, en este artículo nos preguntamos si las reformas introducidas en materia de activación en el Estado de Bienestar español durante la Gran Recesión han repercutido en las relaciones entre los diferentes niveles de gobierno. De esta cuestión se derivan dos conjuntos de preguntas interrelacionadas: (a) ¿Cuál ha sido la orientación de estos cambios? Es decir, ¿se ha revertido el proceso descentralizador que ha caracterizado a este sector de política pública en los últimos años?; (b) ¿Qué factores dan razón de los cambios en la organización territorial de las PAMT en el actual contexto de austeridad y consolidación fiscal?

En este terreno se observan distintos planteamientos y situaciones a nivel internacional. En el caso del Reino Unido, por ejemplo, se han desarrollado respuestas descentralizadoras en aspectos administrativos de la gestión y la provisión de las PAMT, si bien el nivel central de gobierno retiene poderes importantes en materia fiscal y de decisión política (López-Santana, 2015: 206-207). También en Italia o EEUU, países con diferentes configuraciones institucionales, se han implementado reformas descentralizadoras, a través de la transferencia a los gobiernos subnacionales de capacidades en materia de gestión, provisión y financiación de los programas de activación (López-Santana, 2015: 102-157). Holanda, país en que el gobierno central desempeña un papel crucial en la formulación de las políticas públicas, ha seguido asimismo esta tendencia descentralizadora. En este caso, los gobiernos locales tienen la capacidad de decidir sobre el contenido de las PAMT, la organización de la prestación de servicios y los perfiles de los beneficiarios de los diferentes programas (Borghi y van Berkel, 2007; van Berkel et al., 2011: 240). En Francia el proceso de descentralización ha supuesto la atribución de distintos papeles a los diferentes gobiernos subnacionales: las regiones son responsables de los programas de formación, los departamentos ofrecen apoyo en la orientación laboral y los municipios son el nivel de gobierno encargado de promover la inclusión social (van Berkel et al., 2011: 240).

Por otro lado, países como Alemania han seguido la tendencia contraria, procediendo a una centralización de la gobernanza territorial de sus PAMT. Dicha tendencia comenzó con la Ley de Promoción del Empleo de 1969, que capacita al gobierno federal para llevar a cabo la implementación de las PAMT. Esta orientación se ha visto reforzada por la reforma Hartz IV (2005), que ha desplazado hacia el nivel federal la responsabilidad sobre el diseño de las medidas (estandarización de los programas), el establecimiento de

Este trabajo ha sido presentado en varios congresos internacionales y forma parte del proyecto CRIGOBBE (Los efectos de la crisis en la gobernanza del sistema de protección social en España: la perspectiva multinivel y del welfare-mix), que ha sido posible gracias a la financiación proporcionada por el Instituto Nacional de Administración Pública (INAP) en su convocatoria competitiva para el apoyo a proyectos de investigación. Queremos mostrar nuestro agradecimiento a los evaluadores por haber leído nuestro trabajo en profundidad y por las críticas constructivas realizadas. También queremos dar las gracias a Eloisa del Pino, IP del proyecto CRIGOBBE, por sus comentarios y sugerencias a las versiones preliminares de este artículo. 
los derechos y obligaciones de los desempleados beneficiarios de las PAMT, así como los acuerdos fiscales para la financiación de las mismas (López-Santana, 2015: 128-129). Todo ello ha convertido a Alemania en uno de los pocos Estados de Bienestar occidentales en los que las competencias en materia de activación han «viajado» desde los niveles inferiores de gobierno hacia arriba.

Por último, también hay casos híbridos en que ambas tendencias se manifiestan de forma prácticamente simultánea, como por ejemplo Suecia. Este país, incluido dentro de los sistemas de bienestar de tipo socialdemócrata o nórdico ${ }^{2}$, ha combinado a lo largo de los últimos años respuestas centralizadoras con la transferencia de autoridad a los niveles regionales y locales. Entre las primeras se encuentran la eliminación de los programas municipales de juventud en 2007, la fusión de la Junta Nacional del Mercado de Trabajo (órgano intergubernamental en materia de empleo) y las juntas de las regiones (län) en 2008, a costa de la pérdida de influencia de los niveles locales, o la transferencia de la coordinación de las medidas para la integración de los inmigrantes en el mercado de trabajo al Servicio Público de Empleo nacional (PES por sus siglas en inglés) en 2010 (Minas, 2011: 204-205). Sin embargo, en el contexto de la crisis económica iniciada en 2008, y ante el desequilibrio financiero de las autoridades locales (elevados niveles de déficit público) el gobierno central introdujo en 2012 reformas normativas de carácter financiero y administrativo en el mercado de trabajo, para tratar de hacer frente al crecimiento del desempleo. En el sector de la activación, estas medidas, concretadas en el Programa Nacional de Reformas $^{3}$, han permitido a las autoridades locales incrementar su autonomía financiera y una mayor participación en la implementación (diseño y gestión) de las PAMT a través de sus propias oficinas y centros de empleo (Mathias, 2017: 37-38).

En España, el enfoque de la activación arranca a partir de la reforma del sistema de protección por desempleo de 20024, que se enmarca en la Estrategia Europea para el Empleo (EEE) de 1997. En el año 2010 se completó el proceso de descentralización de este sector de política pública al conjunto de las CC.AA, dando lugar a un sistema de gobierno multinivel en el que el Gobierno central ha delegado competencias administrativas a los gobiernos regionales al tiempo que ha conservado los poderes políticos y fiscales (López-Santana, 2015: 159-172).

A partir del inicio de la crisis, los distintos gobiernos centrales han desarrollado varias reformas del mercado de trabajo que han afectado a las PAMT. El contenido sustantivo de estas reformas, los instrumentos y el tipo de programas de activación implementados ya ha sido estudiado (OCDE, 2013; Martin, 2014; Martínez Valverde 2014; Moreira et al., 2015; de la Rica 2015). Sin embargo, hay pocos análisis acerca de cómo han podido afectar estas reformas a la organización territorial de las PAMT en el Estado Autonómico.

Nuestra investigación aplica una metodología basada en el rastreo de procesos (process tracing), centrado en la senda marcada por la propia política pública y el papel constitutivo de las ideas dentro de la noción de cambio o reforma. A través de la observación de la evolución de las PAMT desde mediados de los años 90, y centrándonos especialmente en el periodo comprendido entre 2011 y 2016, esta aproximación nos ha permitido estudiar los mecanismos causales de los cambios y cómo se produce el resultado final (Beach y Pedersen, 2013). Los datos utilizados proceden tanto de fuentes secundarias, fundamentalmente revisión de la bibliografía, notas de prensa, textos legales, documentos políticos e informes sectoriales, como de fuentes primarias, a través de la explotación de entrevistas realizadas a responsables de los ministerios centrales y regionales de empleo ${ }^{5}$.

El artículo se organiza de la siguiente forma: en el apartado que se expone a continuación realizamos una revisión de la literatura sobre los procesos de cambio en la organización territorial de los Estados de Bienestar, en él se plantean además las hipótesis de investigación y se expone el marco analítico utilizado; en el tercero analizamos el caso de las PAMT en España, describiendo la situación previa a la crisis y mostrando los cambios que han tenido lugar en dichas políticas en el contexto de la Gran Recesión; el cuarto apartado está dedicado a indicar qué factores identificados por la literatura han sido determinantes en los procesos de cambio de las PAMT en nuestro país; por último se exponen unas breves conclusiones.

\footnotetext{
2 Este modelo de Estado del Bienestar sería también el propio de países como Dinamarca, Finlandia o Noruega (EspingAndersen, 1990), caracterizados por una configuración territorial con un alto grado de autonomía local en la organización, gestión y financiación de las políticas sociales (OOSTERLYNCK et al., 2013: 17-18).

3 Programa Nacional de Reformas de Suecia 2012, Fuente: http://www.government.se/reports/2012/04/swedens-national-reformprogramme-2012/.

4 Real Decreto-Ley 5/2002 de 24 de mayo de Medidas Urgentes para la Reforma del Sistema de Protección por Desempleo y Mejora de la Ocupabilidad, que terminó plasmándose en la Ley 45/2002 de 12 de diciembre.

5 Para una información más completa sobre el diseño y la metodología de investigación véase la nota incluida al final del artículo.
} 


\section{REVISIÓN DE LA LITERATURA, HIPÓTESIS DE INVESTIGACIÓN Y MARCO ANALÍTICO}

La literatura académica recoge el debate acerca de si la tendencia descentralizadora hacia los niveles subnacionales de gobierno detectada desde finales de los años 70 en los Estados de Bienestar occidentales sigue presente en la actualidad. Desde el federalismo fiscal se apunta que la reciente crisis financiera y económica ha causado perturbaciones y tensiones en las dinámicas federales, las cuales han conducido a una pérdida de discrecionalidad de los gobiernos subnacionales (Braun y Trein, 2014; Trein y Ruiz 2015). Desde un punto de vista politológico, algunos estudios destacan que a partir de 2009, momento en el que la situación económica y financiera de los Estados se agrava, el proceso de toma de decisiones se ha modificado sustancialmente en los países del Sur de Europa, dejando menos espacio de actuación a los niveles político-administrativos subnacionales (León et al., 2015; Pavolini y Del Pino 2015; Guillén y Pavolini, 2015). Sin embargo, ciertos análisis sectoriales han detectado procesos más complejos, según los cuales la gobernanza territorial de las políticas sociales se manifiesta como un fenómeno con diferentes facetas, de modo que mientras algunas de sus dimensiones constitutivas han sufrido cambios sustantivos en las últimas décadas, otras han permanecido en esencia constantes (Humer et al., 2013; López-Santana, 2015).

Por otro lado, una parte la literatura científica que se ha preguntado sobre por qué los países proceden a reorganizar su estructura territorial de poder señala a factores económico-financieros (la crisis económica, la búsqueda de mayor eficacia y eficiencia en el establecimiento de medidas y la consecución de objetivos o la existencia de fuertes restricciones presupuestarias) como variables que pueden determinar estos cambios (OCDE, 2003; Graziano y Raué, 2011; Canavire-Bacarreza y Martínez-Vasquez, 2012). Sin embargo, otros autores han puesto el énfasis en factores de tipo político, social e institucional como la ideología de los gobiernos en el poder, la estructura intergubernamental vigente, las preferencias de los actores o la pertenencia de los países a estructuras de gobierno supranacionales (Pierson, 2001; Greer, 2010; Weishaupt, 2010; Clasen y Clegg, 2011; Graziano, 2012; Bonoli, 2011; Klitgaard et al. 2015; López-Sanatana, 2015, 2016).

En esta investigación estudiaremos el impacto de cuatro variables independientes que pueden ser responsables de los procesos de cambio en la gobernanza territorial de las políticas sociales: (1) la crisis económica y determinados factores asociados a ella, como las restricciones presupuestarias y los objetivos de reducción de costes; (2) la ideología política de los partidos en el gobierno; (3) una configuración institucional en varios niveles de gobierno, y (4) la pertenencia a la Unión Europea (UE) entendida como nivel supranacional de gobierno.

En primer lugar, la búsqueda de mayor eficacia y eficiencia en la gestión de los sistemas de protección por desempleo (SPD) y los objetivos de contención de costes pueden inducir medidas centralizadoras, llevando a los Estados federales y compuestos a modificar su organización territorial en contextos de crisis económica (OCDE, 2003; Graziano y Raué, 2011). De acuerdo con ello, nuestra primera hipótesis, de carácter «económico», es la siguiente:

Hipótesis 1: Los Gobiernos procederán a impulsar medidas centralizadoras en los sistemas de protección por desempleo durante los períodos de crisis económica.

En segundo lugar, la literatura señala que la ideología, más allá de influir en las diferentes respuestas de los gobiernos a la crisis económica en términos de expansión o reducción del gasto social y los derechos sociales (Starke et al. 2014), también es importante a la hora de redistribuir la autoridad política entre los niveles de gobierno en el ámbito de las políticas sociales (Klitgaard et al. 2015; Christiansen y Klitgaard, 2010; Hacker y Pierson 2010). De acuerdo con ello, tanto los partidos de izquierda (para responder a las demandas de autonomía de los distintos territorios) como los partidos liberales (para acomodar las preferencias institucionales a largo plazo de las organizaciones empresariales), favorecerían los procesos de descentralización (Elmelund-Præstekær y Klitgaard, 2012: 951-952), mientras que los partidos conservadores, que en la mayoría de los casos poseen una visión unitaria, serían reticentes a descentralizar el poder político y transferir competencias a los gobiernos subcentrales, salvo cuando necesiten apoyo electoral (Muro, 2009). En tal sentido, nuestra segunda hipótesis, de carácter «político», es la siguiente:

Hipótesis 2: La presencia de un Gobierno central sostenido por un partido conservador o democristiano favorecerá la reducción de la capacidad de decisión de los niveles subnacionales de gobierno.

En tercer lugar, diversos estudios apuntan a las estructuras intergubernamentales vigentes y a la propia estructura del Estado (de tipo federal o compuesto) como factores que restringen las trayectorias institucionales y los procesos de cambio en aquellos países en los que la política de empleo es una competencia 
compartida o es objeto de disputa entre los distintos niveles de gobierno (López-Santana, 2015: 32; Clasen y Clegg, 2011). La presencia de jugadores con capacidad de veto y de situaciones que facilitan el recurso al mismo (una magistratura poderosa, los propios gobiernos regionales y el gobierno central, el bicameralismo o los gobiernos de coalición) (Pierson, 2001: 5; Bonoli, 2010; Greer, 2010: 184-185), serían los factores que determinarían el resultado de la ecuación centralización/descentralización en el terreno de la activación (Weishaupt, 2010: 479). De ello se deriva nuestra tercera hipótesis, de carácter «institucional»:

Hipótesis 3: Los procesos de centralización en las PAMT serán más difíciles de desarrollar en los países donde la política de empleo es una competencia compartida o es objeto de disputa entre diferentes niveles de gobierno.

En cuarto lugar, diferentes autores ponen de relieve el papel jugado por actores de carácter internacional como la UE en el desarrollo de las políticas sociales, incluidas las de activación (Heidenreich y Zeitlin, 2009; Graziano et al., 2011; López-Santana, 2009; Verschraegen et al., 2011). En el ámbito de las políticas de empleo, la verdadera implicación del nivel supranacional de gobierno comenzó con la EEE de finales de los 90 , y las consiguientes reformas a nivel nacional, que priorizaron la inclusión activa de las personas desempleadas en el mercado de trabajo (Bonoli, 2010). Esta estrategia, así como las sucesivas comunicaciones y recomendaciones de las instituciones europeas, se han centrado en el papel que deben desempeñar los niveles subnacionales de gobierno, orientando y fomentado los procesos de descentralización política, administrativa y financiera en este sector de política social (Smismans, 2004, 2006).

Este proceso de europeización de las políticas empleo se da en tres dimensiones distintas (Moreno y Serrano-Pascual, 2011): por un lado, la influencia de la UE tiene una dimensión cognitiva o normativa, a través del establecimiento de ideas, prescripciones o marcos de actuación -que producen lo que se conoce como «framing effect» (López-Santana, 2006)-; en segundo lugar, esta europeización se haría efectiva a través de la definición de procedimientos y regulaciones basadas en un sistema de gobernanza multinivel con participación de los actores y agentes interesados; y por último, la influencia de la UE en el ámbito del empleo se efectúa a través del diseño de indicadores cuantitativos y cualitativos de referencia para el conjunto de los Estados miembros (Guillen et al., 2016: 189). Todo ello complementado con recursos como los asignados el Fondo Social Europeo (FSE), especialmente relevantes en el caso de las PAMT (Verschraegen et al., 2011).

La capacidad explicativa del proceso de europeización, entendido como factor que limita la centralización, se vería incrementada en el caso de los Estados cuyo modelo de organización territorial es más jerárquico, como es el caso de los regímenes de bienestar del Sur de Europa (Graziano, 2012: 321).

Hipótesis 4: En los regímenes de bienestar del Sur de Europa pertenecientes a la UE, la centralización de las PAMT se verá dificultada por el apoyo del nivel supranacional de gobierno a los procesos de descentralización.

Aunque se ha intentado ubicar a distintos países en diferentes clasificaciones o tipos, la gobernanza del Estado de Bienestar en su dimensión territorial no es fácil de aprehender (véase por ejemplo Humer et al. 2013; Kazepov 2010). En el ámbito de la activación, el sentido de los cambios en el eje descentralización/centralización es difícil de analizar incluso a nivel de programas y servicios debido a la implicación de múltiples actores (públicos y privados) y niveles de gobierno (van Berkel et al., 2011). Algunos análisis sectoriales han detectado dinámicas complejas, en las que la gobernanza territorial de las políticas sociales se manifiesta como un fenómeno multidimensional (Braun 2000; van Berkel 2010; Weishaupt 2010; van Berkel y Borghi 2010; López-Santana 2015).

Con el objetivo de atender a la complejidad de la gobernanza territorial y su relación con las políticas sociales, la literatura ha distinguido entre: el componente decisional, más político y que hace referencia al nivel de gobierno que posee la competencia y tiene capacidad para legislar; la implementación, de carácter administrativo y que se refiere a la responsabilidad sobre la gestión, provisión y aplicación; y por último, el componente fiscal, en referencia a quienes son responsables de la financiación de las iniciativas (Humer, 2013: 152-154; López-Santana, 2015: 24-25). En relación con este asunto cabe señalar que en las últimas décadas algunas de las dimensiones antes mencionadas han sufrido cambios sustantivos, mientras otras han permanecido básicamente inalteradas (Hooghe and Marks, 2001; López-Santana 2015).

Aunque la anterior distinción es imperfecta (en la fase de implementación, por ejemplo, se adoptan decisiones sobre el tipo de programas y servicios o la definición de los grupos objetivo), consideramos que es la mejor forma de acercarse a la complejidad del objeto de estudio. Si bien las políticas sociales se encuentren descentralizadas, los ministerios sectoriales centrales han podido reservarse poderes relacionados con la decisión, la fi- 
nanciación y la implementación. Además, creemos que en época de crisis el Estado central también puede tratar de intervenir en las políticas sectoriales desde los ministerios horizontales (en particular, desde el Ministerio de Hacienda). Por último, conviene no olvidar que los cambios pueden haberse producido formalmente, de modo que hayan dejado un «rastro» normativo, o informalmente (ver por ejemplo Braun 2000; López Santana 2015).

\section{LAS TRANSFORMACIONES DE LA GOBERNANZA TERRITORIAL EN LAS POLÍTICAS ACTIVAS DEL MERCADO DE TRABAJO EN ESPAÑA}

\section{Antecedentes}

El sistema de gobernanza territorial de las PAMT se ha conformado progresivamente a partir de 1990, impulsado por los sucesivos gobiernos socialdemócratas (PSOE) y conservadores (PP), a través de acuerdos bilaterales con las distintas CC.AA. La Ley de Empleo de 2003 suprime el monopolio del Gobierno central sobre estas políticas y constituye un hito particularmente reseñable en este proceso, que culmina en 2010 y supone la transferencia de las competencias administrativas, de gestión, organización y ejecución en dicha materia.

En las páginas siguientes se exponen los principales rasgos del sistema en lo que se refiere a las capacidades de decisión, financiación e implementación que corresponden a los distintos actores.

\section{Decisión}

Al Estado central le corresponde establecer la legislación básica ${ }^{6}$ en la materia, el diseño de las líneas generales de la política, la supervisión de su aplicación por parte de los Servicios de Empleo Públicos Regionales (SEPR), los mecanismos de coordinación y cohesión, así como la recopilación de estadísticas a nivel nacional. Su actuación se canaliza a través del Sistema Público de Empleo Estatal (SEPE)

Las CC.AA, por su parte, tienen la capacidad de decidir sobre la administración, gestión, organización y provisión de las PAMT a través de los SEPR. También dictan normas que complementan la legislación básica del Estado, al tiempo que hacen cumplir las condicionalidades y sanciones impuestas por el Gobierno central. En resumen, los gobiernos regionales tienen cierta capacidad para organizarse y administrar sus políticas dentro de los límites del mandato nacional. Los gobiernos locales, por su parte, participan en el proceso de concertación de las PAMT en las CC.AA a través de su representación en los SEPR.

En este sistema multinivel juega un papel fundamental la Conferencia Sectorial de Empleo y Asuntos Laborales (CSEAL) ${ }^{7}$. Se trata de un órgano intergubernamental de carácter formal, con capacidad para llegar a acuerdos que vinculen a los firmantes, integrado por el Ministro de Trabajo y Asuntos Sociales y por los Consejeros de las CC.AA con competencias en la materia. Tiene capacidad de decisión en el establecimiento de acuerdos en materia de coordinación de la política de empleo, aprobación de los Planes Anuales de Política de Empleo (PAPE), fijación de los objetivos y orientaciones de las PAMT y establecimiento de criterios tanto para la ejecución de dichas políticas como para la distribución y las condiciones de gestión de los fondos que el Gobierno central destina a las mismas. En el proceso de toma de decisiones cada gobierno representa un único voto. Los acuerdos, dictámenes o recomendaciones surten efectos a partir de su aprobación por la Conferencia. Para la adopción de dichos acuerdos se requiere el voto favorable del Gobierno central y el de la mayoría de las CC.AA. A través de este órgano intergubernamental de coordinación, colaboración, cooperación y evaluación, el Gobierno central trata de supervisar la actuación de las comunidades en materia de PAMT (López-Santana y Moyer, 2012: 778).

Por su parte la UE, a través de la normativa y de la difusión de conceptos como «flexiseguridad» (Viebrock y Clasen, 2008), «envejecimiento activo», o del establecimiento de indicadores para la evaluación de las PAMT, contribuye a la generación de un «framing effect» (López-Santana, 2006). En cualquier caso, hay que tener presente que la gobernanza de las políticas sociales en la UE se lleva a cabo bajo el Método Abierto de Coordinación (MAC), caracterizado por la presencia de una base legal débil, la voluntariedad y la flexibilidad. Por tanto, cabe afirmar que la responsabilidad última sobre la regulación de las PAMT está en manos de los gobiernos nacionales (de la Porte y Pochet, 2012; de la Porte y Weishaupt, 2013; de la Porte y Heins, 2015).

\footnotetext{
6 Ley 56/2003, de 16 de diciembre, de Empleo.

7 Regulada por las leyes 42/1997 (art.16) y 56/2003 (art. 7), así como por el Real Decreto 1722/2007 (arts. 5, 6 y 7). Cuenta con un reglamento de funcionamiento propio, disponible en: http://www.seap.minhap.gob.es/dms/es/web/areas/politica_autonomica/ coop_autonomica/Conf_Sectoriales/Conf_Sect_Regl/parrafo/O/R_CS_AsuntosLaborales.pdf.
} 


\section{Financiación}

La financiación de las PAMT se apoya en tres pilares. En primer lugar, el Estado central, que retiene la mayor parte de los poderes fiscales y asume el grueso de la carga (López-Santana, 2015: 171-172). El Gobierno central negocia con cada una de las CC.AA una cantidad fija destinada a tal fin. La negociación se lleva a cabo a través de reuniones bilaterales informales que implican tanto a políticos como a técnicos (del SEPE y del SEPR correspondiente). El reparto de estos fondos, que denominaremos estatales y que proceden de los Presupuestos Generales del Estado (Martínez Valverde 2014: 18), es aprobado posteriormente en las reuniones anuales de la CSEAL. Estos recursos, en el periodo previo a la crisis, se distribuían en tres apartados (formación, empleo y modernización de los SEPR) y eran gestionados por las CC.AA en función de sus propias prioridades a la vista de las condiciones vigentes en sus respectivos territorios.

En segundo lugar, los recursos propios de las CC.AA, que se destinan fundamentalmente a cubrir los gastos corrientes y de inversión vinculados a las competencias asumidas en materia de legislación laboral.

Por último, los fondos estructurales procedentes de la UE, principalmente a través del FSE. Los recursos del FSE operan de acuerdo con el principio de cofinanciación, según el cual los fondos europeos deben ir acompañados de fondos estatales. Dicha cofinanciación puede variar entre el 50 y el $80 \%$ del coste total de las intervenciones, en función de una serie de factores socioeconómicos. La gestión de los fondos procedentes de la UE es compartida: las líneas de actuación del FSE se diseñan a nivel europeo, aunque su desarrollo mediante la selección de los proyectos y el seguimiento de los mismos es responsabilidad de los gobiernos nacionales y regionales. Esta fuente de recursos es clave en la construcción de la capacidad administrativa necesaria para aplicar a nivel local las PAMT y representa un incentivo para la cooperación intergubernamental (López-Santana, 2016: 121-122). El Gobierno central es el encargado, a través de la Unidad Administradora del Fondo Social Europeo (UAFSE), de administrar los recursos, así como de controlar y evaluar las iniciativas de activación. Aún así, tal y como apuntan los informantes consultados en los distintos servicios de empleo regionales, el control central sobre la gestión de los fondos europeos es más flexible que el llevado a cabo sobre los fondos estatales.

\section{Implementación}

La implementación de las PAMT es competencia de todos los gobiernos regionales desde 2010, momento en que se completa el proceso de descentralización de la política. Los gobiernos regionales son los encargados del desarrollo de ésta en sus territorios a través de sus respectivos SEPR.

\section{Los cambios acaecidos en el marco de la Gran Recesión}

Desde el inicio de la crisis los distintos Gobiernos centrales han impulsado varias reformas del mercado de trabajo, que han afectado de manera significativa a las PAMT en el periodo comprendido entre 2011 y 2016.

Si bien es cierto que, desde el punto de vista de la organización territorial de las PAMT, la reforma introducida por el ejecutivo socialista en 2011 tuvo un carácter descentralizador, no fue así en el caso de las iniciativas desarrolladas por el Gobierno del PP a partir de 2012.

Antes de su salida del Gobierno central, el PSOE llevó a cabo una reforma del sistema en colaboración con los gobiernos regionales ${ }^{8}$. Dicha reforma transformó la estructura vigente hasta ese momento, en la que los programas de activación estaban fijados por el Estado, otorgando a las CC.AA la posibilidad de adaptarlos a las especificidades de su mercado laboral, al tiempo que abrió la puerta al desarrollo de medidas complementarias por parte de los gobiernos locales, pese a carecer éstos de competencias específicas en la materia (Martínez Valverde, 2014: 15-17).

Por su parte, las medidas introducidas por el Gobierno del PP ${ }^{9}$ se han centrado en los incentivos a la contratación y el autoempleo, la formación y el aprendizaje (Moreira et al., 2015: 204). Estas iniciativas han generado efectos relevantes sobre el sistema de gobernanza territorial en sus dimensiones decisional, financiera y administrativa.

8 Real Decreto-Ley 3/2011, de 18 de febrero.

9 Real Decreto-Ley 20/2012; Real Decreto 1529/2012; Real Decreto 189/2013; Real Decreto-Ley 4/2013; Real Decreto-Ley 16/2013; Real Decreto-Ley 3/2014; Real Decreto-Ley 8/2014; Real Decreto Legislativo 3/2015, de 23 de octubre, por el que se aprueba el texto refundido de la Ley de Empleo. 
El nuevo sistema de gobernanza de las PAMT, acordado en el seno de la CSEAL ${ }^{10}$, se articula a través de tres instrumentos: la Estrategia Española de Activación para el Empleo (EEAE), los PAPE y el Sistema de Información de los Servicios Públicos de Empleo (SISPE). La EEAE (2014-2016) y su concreción anual, los PAPE, se configuran como los principales instrumentos del Gobierno central para la coordinación de las PAMT en el conjunto del Estado, recogiendo los objetivos a alcanzar por las CC.AA, el marco presupuestario, las fuentes de financiación y las condiciones de gestión de los fondos estatales. Veamos cuál ha sido el impacto de estos instrumentos y los cambios que han tenido lugar en la gobernanza territorial de dichas políticas.

\section{Decisión}

Desde un punto de vista formal, las medidas en materia de activación no han supuesto una modificación de la dimensión decisional, ya que el Gobierno central posee competencias en materia de legislación básica en el ámbito de empleo, y ha utilizado esta facultad normativa para ejercer su influencia a través del SEPE. Ahora bien, el nuevo marco normativo constituido por la EEAE condiciona el contenido de las decisiones a través del establecimiento de los principios de actuación, la regulación específica de las medidas de activación propias de las CC.AA (Reglamento de empleo) y el poder otorgado a la Dirección General del SEPE (único organismo con capacidad de modificar los servicios y programas, tanto comunes como propios, contenidos en los PAPE).

A nivel europeo, a través de iniciativas horizontales y no sectoriales, se han adoptado decisiones que afectan a las PAMT (de la Porte y Heins, 2015). Los nuevos desarrollos normativos en materia de coordinación de la política fiscal (Six Pack, Two Pack o Pacto fiscal) han modificado el papel tradicional de la UE en estas políticas a través del MAC (Moreno y Serrano-Pascual, 2008: 37). Estos instrumentos fiscales, concretados a nivel nacional en las recomendaciones del Consejo relativas a los programas nacionales de reforma, han sido claves en la transformación del modelo de gobernanza de las políticas activas recogida en la EEAE, orientándolas hacia la eficacia, la consecución de resultados en base a objetivos de política fiscal y el incremento de la rendición de cuentas ex ante y ex post por parte de los gobiernos regionales.

También se han producido cambios tanto en la lógica de funcionamiento de la CSEAL como en el tipo de decisiones que adopta. Desde la llegada de la crisis su funcionamiento ha estado marcado por una lógica predominantemente político-partidista. La existencia de una mayoría de gobiernos del PP ha contribuido a reforzar la posición del Gobierno central. Según manifiesta el responsable de uno de los servicios de empleo público regional, esta mayoría política «ha puesto en una posición de ventaja muy predominante al Estado en la CSEAL, evidenciada en la tendencia del Ministerio de Trabajo y Asuntos Sociales a intentar actuar como director de las CC.AA en materia de activación», opinión que refleja en buena medida la posición del conjunto de los actores autonómicos. Por otro lado, la CSEAL se ha configurado como un órgano centrado en las decisiones de carácter económico, atendiendo casi en exclusiva al reparto de los fondos. A diferencia del periodo previo a la crisis, los nuevos desarrollos normativos de carácter técnico (como los estándares de calidad de la formación profesional para el empleo, por ejemplo) han sido aprobados por el Gobierno central de manera unilateral, sin negociación con las comunidades en el marco de la conferencia sectorial.

Por último, los actores subnacionales perciben que se ha producido una centralización de la dimensión decisional a raíz de los nuevos desarrollos normativos. Desde las CC.AA se señala que la normativa básica estatal y los instrumentos que establece el Ministerio de Empleo y Seguridad Social limitan su margen de maniobra.

\section{Financiación}

En este ámbito es preciso destacar la reorganización de los fondos estatales mediante la creación de «bloques» y partidas de financiación finalistas. Un primer bloque ha ido destinado en exclusiva a la financiación de la intermediación laboral realizada a través de las agencias de colocación ${ }^{11}$, en detrimento de

10 CSEAL de 11 de abril de 2013. Nota de prensa: Ministerio de Empleo y Seguridad Social. http://prensa.empleo.gob.es/WebPrensa/noticias/laboral/detalle/2078.

11 Acuerdo Marco de intermediación laboral, contenido en el Real Decreto-Ley 4/2013, de 22 de febrero. Este nuevo instrumento tiene como objetivo complementar la intermediación de los servicios públicos de empleo mediante la colaboración con la iniciativa privada. En un principio la medida contó con el respaldo de todas las CC.AA salvo Andalucía, País Vasco y Cataluña, de un color político diferente al del Gobierno central. Tras las elecciones de 2015 también han abandonado el acuerdo marco Extremadura, Baleares, Valencia, Castilla-La Mancha y Aragón. 
los Planes de empleo públicos, la contratación de los Ayuntamientos o las ayudas a la movilidad laboral interregional. De acuerdo con los responsables autonómicos entrevistados, dicha orientación finalista ha provocado que muchos gobiernos regionales hayan dejado de percibir fondos por no realizar contratos con las agencias de colocación. Otro ejemplo de la nueva orientación finalista de la financiación lo encontramos en el PAPE de 2016, según el cual las CC.AA deben dedicar una parte de los fondos recibidos a programas de atención a los desempleados de larga duración que reúnan determinadas características ${ }^{12}$.

Asimismo, el nuevo sistema de financiación ha pasado a depender progresivamente del grado de cumplimiento de unos objetivos, comunes para todas las CC.AA, vinculados al rendimiento de las PAMT. EI Gobierno central, siguiendo las recomendaciones del Consejo de la UE y en línea con los principios introducidos en diversos instrumentos de política social, hace hincapié en la introducción de condiciones para la obtención de los fondos (Graziano, 2012).

Tal como recoge la EEAE 2014-2016: "La clave del cambio al nuevo modelo de políticas activas de empleo está en un nuevo marco basado en la evaluación». Para ello se establece un sistema de indicadores que permite medir el grado de cumplimiento de los objetivos fijados en los PAPE. De esta forma, mientras una parte de los fondos procedentes del Gobierno central (el denominado «marco general») se concede en función de una serie de indicadores socioeconómicos y de empleo, otra está vinculada al cumplimiento de los objetivos contenidos en los PAPE. Esta segunda parte de la financiación ha pasado de representar un $15 \%$ de los fondos destinados a las PAMT en 2013 a un 70\% en 2016. Según expresan los representantes de las CC.AA, el nuevo sistema hace que la financiación dependa en mayor medida de los resultados que de las necesidades reales en materia de inserción laboral.

Desde que comenzara la crisis se aprecia una reducción en los fondos (tanto estatales como europeos) destinados a las PAMT, lo que implica a su vez un cambio en la participación de los diferentes niveles de gobierno en su sostenimiento. De acuerdo con los datos del Gráfico 1, el gasto público dedicado a las políticas activas en 2014 era algo más de la mitad del correspondiente al momento de inicio de la crisis, representando el $0,44 \%$ del PIB, por debajo de la media de los países de la OCDE.

A juicio de Negueruela (2015) el descenso en la cuantía de los recursos estatales ha sido especialmente intenso en el caso de las CC.AA más pobres, destacando los casos de Andalucía (con una disminución del 93\%), Castilla-La Mancha y Extremadura (un $91 \%$ ) y Galicia (un $85 \%$ ).

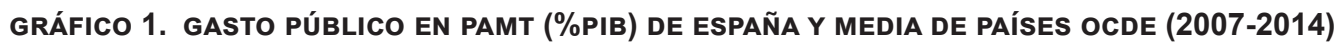

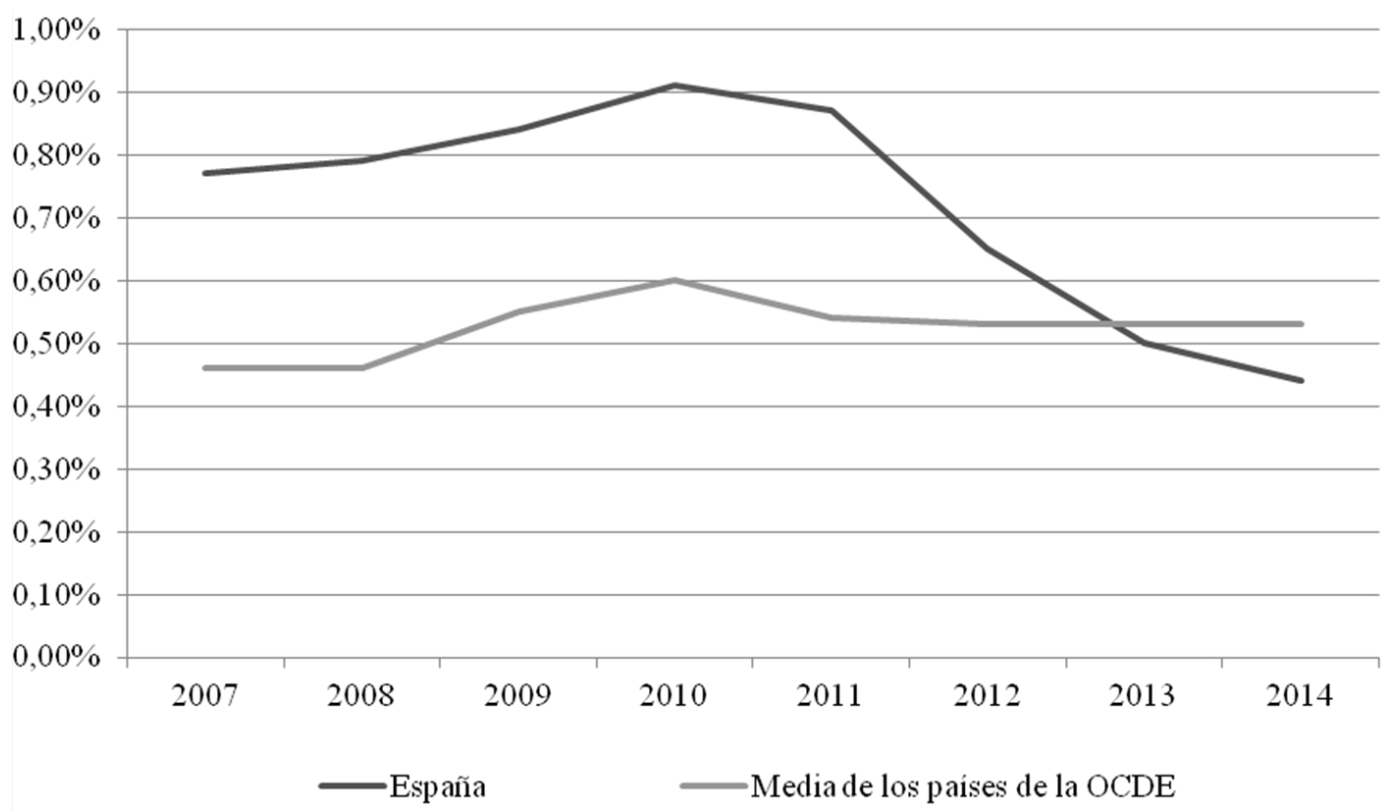

Fuente: Elaboración propia a partir de OCDE. Stat. https://stats.oecd.org/Index.aspx?DataSetCode=LMPEXP\# Consultado el 15 de mayo de 2017

12 Resolución de 22 de agosto de 2016, de la Secretaría de Estado de Empleo, por la que se publica el Acuerdo del Consejo de Ministros de 5 de agosto de 2016. 
La financiación procedente de la UE, por su parte, ha caído en un $18 \%$ en términos absolutos (ver Gráfico 2). Un descenso que se debe al propio funcionamiento de los fondos estructurales (fundamentalmente el FSE), basados en un sistema de retorno de la financiación de los recursos ejecutados, que se ve afectado por el contexto estabilidad presupuestaria y la imposición de techos de gasto por parte del Gobierno central a las CC.AA ${ }^{13}$.

Como muestra el Gráfico 2, si en términos relativos en el periodo que va de 2008 a 2011 el Gobierno central aportaba el $80 \%$ de recursos y el FSE era responsable del $20 \%$, en el periodo 2012-2015 los fondos estatales representan poco más del $60 \%$ y el FSE en torno al $40 \%$. Dado que los recursos procedentes del FSE están sometidos a una mayor flexibilidad en la gestión y un menor control (López-Santana, 2016: 128), el incremento de la participación de la UE en la financiación total de este sector de política pública ha provocado que los niveles subnacionales de gobierno puedan experimentar, más que en el periodo previo a la crisis, con los programas de activación, atendiendo de esta forma a las condiciones vigentes en sus territorios. Desde el servicio de empleo público de una de las CC.AA seleccionadas, se afirma que, en buena medida, gracias a los recursos provenientes del FSE «han podido realizar acciones innovadoras, muy adaptadas al territorio, y buscar nuevas soluciones al problema del desempleo».

GRÁFICO 2. DISTRIBUCIÓN DE FONDOS DEL ESTADO Y DE LA UNIÓN EUROPEA (EN MILES DE €) GESTIONADOS POR LAS CC.AA

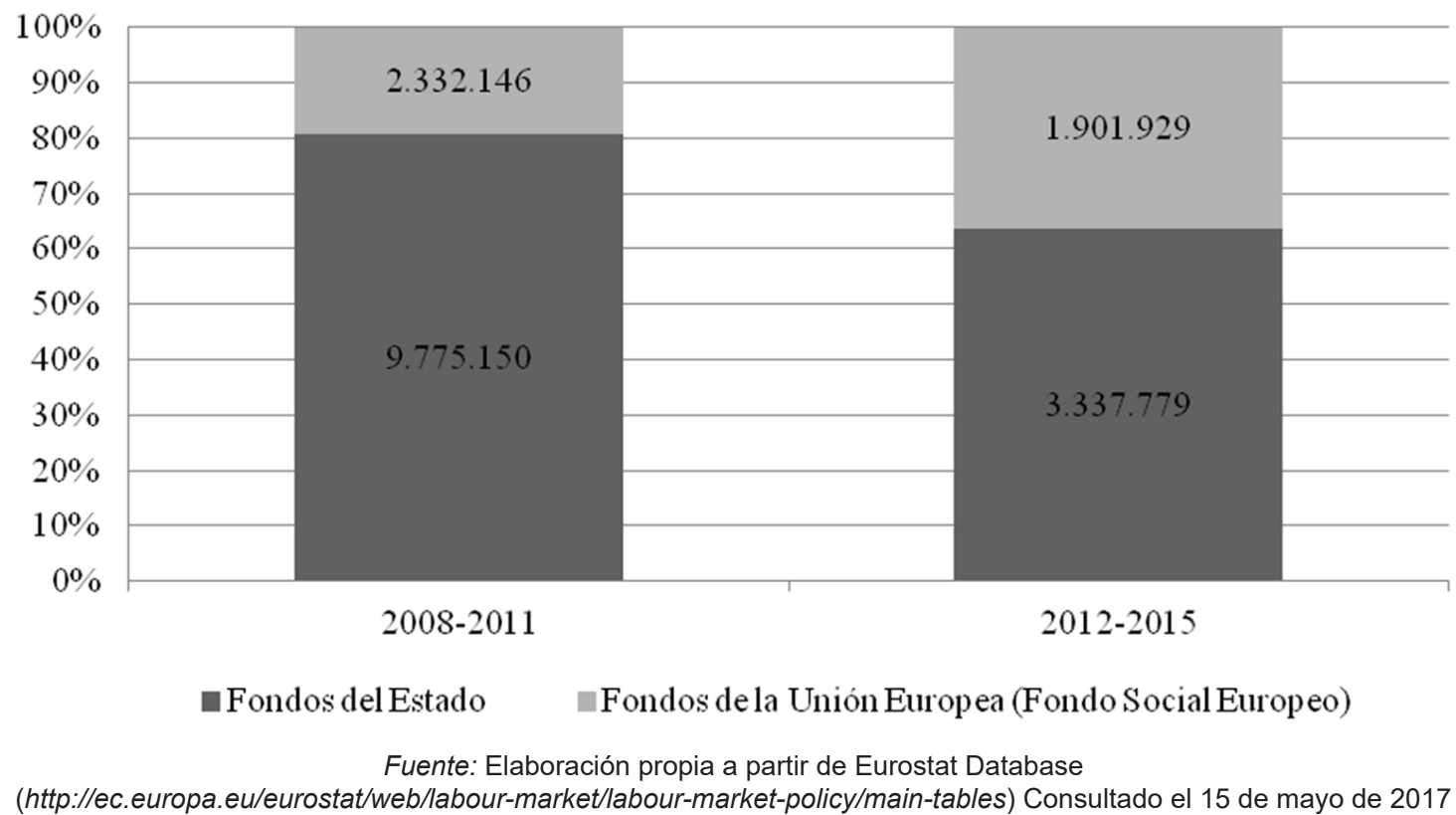

\section{Implementación}

Los distintos programas y servicios de activación ${ }^{14}$, tanto los de aplicación para todo el Estado como los propios de cada comunidad, siguen siendo gestionados por las CC.AA a través de sus SEPR. En este sentido no ha habido cambios por lo respecta al nivel de gobierno que implementa las PAMT. Las CC.AA tienen la responsabilidad de decidir en materia de orientación, igualdad en el acceso al empleo y sobre los procedimientos de intermediación con agencias de colocación. Es decir, la implementación de estas medidas se lleva a cabo a través de la propia estructura regional. Sin embargo, en materia de formación, oportunidades de empleo y mejora del marco institucional, las decisiones son compartidas con el Gobierno central, con escaso margen de decisión para las comunidades.

13 De acuerdo con los responsables autonómicos de los servicios de empleo entrevistados, «en los últimos 4 años se han perdido fondos europeos porque no se han podido gastar previamente, como por ejemplo los relacionados con el Programa de Garantía Juvenil». Una opinión compartida por el resto de informantes del nivel regional consultados en esta investigación.

14 Estos se enmarcan en los seis ejes prioritarios de actuación establecidos por el Gobierno central en la EEAE (2014-2016), aunque ya estaban presentes en el PAPE de 2013. 
GAPP. Nueva Época - N. 18, noviembre 2017 - ISSN: 1989-8991 - DOI: 10.24965/gapp.v0i18.10433 - [Págs. 5-22]

La centralización de la gobernanza territorial en las políticas activas del mercado de trabajo en España... Jorge José Hernández-Moreno / Juan Antonio Ramos Gallarín

TABLA 1. SERVICIOS Y PROGRAMAS DE ACTIVACIÓN CONTENIDOS EN LOS PROGRAMAS ANUALES DE EMPLEO (2013-2016)

\begin{tabular}{|c|c|c|c|c|c|c|c|c|}
\hline \multirow{2}{*}{ Tipos de medidas } & \multicolumn{4}{|c|}{ Servicios* ${ }^{*}$ Programas ${ }^{* *}$ comunes SNE } & \multicolumn{4}{|c|}{ Servicios y Programas propios SEPR } \\
\hline & 2013 & 2014 & 2015 & 2016 & 2013 & 2014 & 2015 & 2016 \\
\hline Orientación & 7 & 7 & 11 & 12 & 43 & 62 & 54 & 77 \\
\hline Formación & 9 & 9 & 13 & 13 & 63 & 92 & 103 & 123 \\
\hline Oportunidades de empleo & 6 & 6 & 7 & 7 & 70 & 94 & 102 & 133 \\
\hline $\begin{array}{l}\text { lgualdad en el acceso } \\
\text { al empleo }\end{array}$ & 3 & 3 & 4 & 4 & 20 & 26 & 25 & 20 \\
\hline Emprendimiento & 7 & 5 & 9 & 9 & 72 & 62 & 62 & 78 \\
\hline $\begin{array}{l}\text { Mejora del marco } \\
\text { institucional }\end{array}$ & 4 & 4 & 7 & 7 & 39 & 51 & 20 & 47 \\
\hline Total & 36 & 34 & 51 & 52 & 307 & 387 & 366 & 478 \\
\hline
\end{tabular}

Fuente: Elaboración propia a partir de los PAPE 2013, 2014, 2015, 2016

* Servicios («Acciones», según la terminología de la Ley de Empleo). Se prestan de forma continua y sostenida en el tiempo y buscan atender derechos o responder a las necesidades de personas o empresas.

** Programas («Medidas», según la terminología de la Ley de Empleo). Actuaciones dirigidas a la consecución de objetivos concretos.

La Tabla 1 muestra la evolución de los servicios y programas de activación, en función del eje de actuación (tipos de medidas), a partir de la implantación del nuevo sistema contemplado en el PAPE correspondiente a 2013. A partir de dicho año el número de medidas comunes a todo el Estado, así como las propias de cada CA se han incrementado en todos los ejes de actuación. Dentro de las PAMT que son reguladas directamente por el Gobierno central destacan las iniciativas de orientación y formación para el empleo, centradas en el asesoramiento de las personas beneficiarias, en mejorar su cualificación y facilitar su inserción laboral. Por lo que toca a los servicios y programas propios de las CC.AA, destaca el crecimiento de las medidas de formación y de las incluidas en el eje «oportunidades de empleo», centradas en los incentivos a la contratación y el mantenimiento de los puestos de trabajo a través de instrumentos como las bonificaciones fiscales, beneficios laborales, o incentivos negativos como la reducción o condicionalidad de las prestaciones así como la imposición de sanciones. En términos comparados, durante el periodo 2013-2016, un 85\% del total de los servicios y programas implementados han sido diseñados por los SEPR y adaptados a la realidad del tejido productivo y las personas desempleadas de cada CA.

Sin perjuicio de que, como hemos visto, las CC.AA siguen teniendo un amplio margen de maniobra en relación al diseño y elección de los programas y servicios de activación, el Gobierno central ha puesto en marcha una serie de actividades con una clara intención centralizadora que comentamos a continuación.

Para el seguimiento exhaustivo de la gestión de las PAMT, se ha desarrollado el Servicio de Información de los Servicios Públicos de Empleo. Se trata de una plataforma diseñada en exclusiva por el Gobierno central, en la que cada comunidad debe introducir las medidas implementadas y los resultados de inserción laboral obtenidos. Los resultados de esta evaluación, como se ha comentado, son utilizados para condicionar en torno al $70 \%$ de la financiación procedente del Estado.

Asimismo, el Gobierno central ha tratado de desarrollar instrumentos normativos que estandaricen los servicios y programas de activación para todas las CC.AA. Así cabe entender la Cartera Común de Servicios del Sistema Nacional de Empleo (Real Decreto 7/2015, de 16 de enero), los Reglamentos de Empleo y Formación (Real Decreto-ley 4/2015, de 22 de marzo) y el Programa de Buenas Prácticas. En el momento de cerrar este trabajo dichos instrumentos son objeto de un proceso de negociación caracterizado, de acuerdo con los responsables de las CC.AA, por la falta de transparencia y diálogo entre los distintos niveles de gobierno. En este sentido, la opinión compartida por los representantes regionales de los servicios de empleo es que el Gobierno central actúa de manera unilateral en las reuniones técnicas de coordinación, a pesar de que dichos instrumentos deben ser aprobados por la CSEAL. 
Además, tras la aprobación de la EEAE (2014-2016) y la reforma de la Ley de empleo de 2015, la Dirección General del SEPE pasa a convertirse en el único departamento con capacidad para adaptar y modificar, de acuerdo con los objetivos e intereses del Gobierno central, los servicios y programas de activación regionales.

Por último, merece la pena señalar que la percepción de todos los entrevistados en el nivel autonómico es que el Gobierno central, a través del SEPE, se ha encargado más de dirigir a los restantes niveles de gobierno implicados en las PAMT que de coordinarlos. En este sentido algunos de sus representantes llegan a afirmar que se sienten más bien como «delegaciones regionales», con muy poca autonomía.

\section{FACTORES EXPLICATIVOS DEL NUEVO MODELO DE GOBERNANZA TERRITORIAL DE LAACTIVACIÓN}

Como hemos tenido ocasión de ver en el apartado anterior, a lo largo de los últimos años se han producido cambios de cierta importancia en distintos aspectos del sistema de gobernanza territorial de las PAMT en nuestro país. En las páginas siguientes se hace un repaso a los distintos grupos de factores identificados por la literatura que han influido en las transformaciones antes expuestas.

\section{El contexto socio-económico}

La crisis financiera y económica ha sido uno de los factores que ha impulsado la reforma de la gobernanza de las PAMT por parte del Gobierno central. Así, son frecuentes las referencias a la crisis en los desarrollos normativos en este terreno. Lo dicho se aprecia con claridad, por ejemplo, en la redacción de textos legales dentro del ámbito del mercado de trabajo, como la reforma laboral llevada a cabo por el Gobierno central en $2012^{15}$. También en medidas sectoriales propias del ámbito de la activación, como la EEAE (20142016), en la que se hace mención al contexto de crisis y la necesidad de buscar mayor eficacia y eficiencia en la gestión de los sistemas de protección por desempleo ${ }^{16}$.

De esta forma la crisis económica (y los consiguientes efectos sobre el mercado de trabajo) se configura como una variable que explica en parte el proceso centralizador en materia de activación, basado en el establecimiento de medidas que persiguen la consecución de objetivos (como la consolidación fiscal) así como una gestión más eficiente y eficaz de los sistemas de protección por desempleo por parte de los niveles centrales de gobierno (Graziano y Raué, 2011).

\section{El papel de la ideología}

El proceso de descentralización de las PAMT, desde sus inicios en la década de los 90 hasta la llegada de la crisis, no parece haber respondido esencialmente a la orientación pro-gobiernos subnacionales ni a la visión unitaria y centralista atribuidas respectivamente a los partidos de izquierda y a los partidos conservadores por una parte de la literatura académica. La transferencia de las competencias en materia de activación se ha desarrollado de manera progresiva, tanto con gobiernos del PSOE como del PP (ver la Tabla 2). Sin embargo, en el contexto de la Gran Recesión, sí podemos observar de manera más matizada cómo ha operado este factor.

15 «La gravedad de la situación económica y del empleo descrita exige adoptar una reforma inmediata que proporcione a los operadores económicos y laborales un horizonte de seguridad jurídica y confianza en el que desenvolverse con certeza para conseguir recuperar el empleo. La extraordinaria y urgente necesidad que exige el artículo 86 de la Constitución Española para legislar mediante real decreto-ley se justifica por la situación del mercado laboral español. Este real decreto-ley pretende crear las condiciones necesarias para que la economía española pueda volver a crear empleo y así generar la seguridad necesaria para trabajadores y empresarios, para mercados e inversores» (Real Decreto-ley 3/2012, de 10 de febrero, de medidas urgentes para la reforma del mercado laboral).

16 «La profunda crisis económica y financiera internacional iniciada en 2007, ha tenido un efecto directo sobre los niveles de desempleo en todos los países de la UE-28, y especialmente en España. [...] Además, el nuevo contexto económico obliga a incrementar la eficiencia en la utilización de fondos públicos. La respuesta a esta necesidad tiene su reflejo inmediato en la Ley Orgánica 2/2012, de 27 de abril, de Estabilidad Presupuestaria y Sostenibilidad Financiera, que también afecta al desarrollo de las políticas de activación para el empleo» (Real Decreto 751/2014, de 5 de septiembre, por el que se aprueba la Estrategia Española de Activación para el Empleo 2014-2016). 
GAPP. Nueva Época - N. 18, noviembre 2017 - ISSN: 1989-8991 - DOI: 10.24965/gapp.v0i18.10433 - [Págs. 5-22]

La centralización de la gobernanza territorial en las políticas activas del mercado de trabajo en España... Jorge José Hernández-Moreno / Juan Antonio Ramos Gallarín

tABLA 2. PROCESO De DescentRALIZACión DE LAS PAMt (1990-2010)

\begin{tabular}{|c|c|c|c|c|c|c|c|}
\hline & \multicolumn{7}{|c|}{ Año de descentralización de las PAMT } \\
\hline & 1990 & 1999 & 2000 & 2001 & 2002 & 2003 & 2010 \\
\hline $\begin{array}{l}\text { Partido en el Gobierno } \\
\text { central }\end{array}$ & PSOE & PP & PP & PP & PP & PP & PSOE \\
\hline $\begin{array}{l}\text { CC.AA que reciben } \\
\text { las competencias } \\
\text { de activación }\end{array}$ & $\begin{array}{l}\text { Cataluña } \\
\text { Galicia }\end{array}$ & $\begin{array}{l}\text { Valencia } \\
\text { Canarias } \\
\text { Navarra }\end{array}$ & Madrid & $\begin{array}{l}\text { Extremadura } \\
\text { Asturias }\end{array}$ & $\begin{array}{l}\text { Castilla y } \\
\text { León } \\
\text { Islas } \\
\text { Baleares } \\
\text { La Rioja } \\
\text { Cantabria } \\
\text { Aragón }\end{array}$ & $\begin{array}{l}\text { Castilla-La } \\
\text { Mancha } \\
\text { Andalucía } \\
\text { Murcia }\end{array}$ & $\begin{array}{l}\text { País } \\
\text { Vasco }\end{array}$ \\
\hline
\end{tabular}

Fuente: Elaboración propia

Las medidas en materia de activación introducidas por el segundo gobierno del socialista Rodríguez Zapatero (2008-2011) ${ }^{17}$ se caracterizaron por la atención a las demandas de los niveles subnacionales de gobierno, otorgando a las CC.AA la posibilidad de adaptar y flexibilizar las medidas a desarrollar de acuerdo con las características específicas de su mercado laboral a través de la Estrategia Española de Empleo 2012-2014 (recogida en el Real Decreto 1542/2011), y culminando el proceso de transferencia en materia de activación al País Vasco en 2010.

En contraste, el gobierno conservador del Presidente Rajoy sí ha introducido medidas de carácter centralizador. Así lo expresa alguno de los informantes consultados, que pone como ejemplo la eliminación de parte de la legislación contemplada en la Estrategia Española de Empleo de 2011, la cual ponía en marcha un «reloj» por el que los Programas Nacionales pasaban en un plazo de seis meses a ser programas de libre definición, ajustándose a la estrategia nacional, pero partiendo de cero y adaptándose a las peculiaridades de los mercados de trabajo de las distintas CC.AA.

El papel de la ideología también lo encontramos reflejado en las preferencias y actuaciones de las CC.AA. Un ejemplo concreto lo constituye de nuevo el Acuerdo Marco de intermediación laboral, mediante el cual se incluye al sector privado en la labor de inserción laboral de los desempleados. Comunidades como Aragón, Andalucía, Baleares, Extremadura o Castilla-La Mancha, gobernadas a partir de 2015 por partidos de izquierdas, han decidido no suscribir este acuerdo por razones «ideológicas».

A la vista de lo anterior, cabe afirmar que, en el contexto de la crisis, la reforma de la gobernanza territorial de las PAMT se adecúa a las preferencias ideológicas tanto de los partidos de izquierdas como de los conservadores.

\section{El contexto político/institucional}

El contexto político en el periodo considerado está marcado, a nivel nacional, por la mayoría parlamentaria que apoya al Gobierno presidido por Rajoy, así como por la coincidencia de dicho color político con el vigente en los gobiernos de la mayoría de las CC.AA desde el año 2011. En el ámbito de la activación es clave el papel jugado por la CSEAL. De acuerdo con los representantes de las CC.AA entrevistados, «la primacía mono-color» de esta conferencia sectorial ha dado mucho poder al Gobierno central, menos necesitado de negociar el contenido de desarrollos normativos como la EEAE, o los nuevos Reglamentos de Empleo y Formación.

Este contexto político de claras mayorías partidistas ha favorecido asimismo el rol y las preferencias de determinados departamentos centrales como la Dirección General del SPEE que, recordamos, ha pasado a convertirse en el único organismo con capacidad para modificar los servicios y programas (tanto comunes como propios de cada CA) contenidos en los PAPE, aún habiendo sido aprobados por la CSEAL.

17 Real Decreto-Ley 3/2011, de 18 de febrero, de medidas urgentes para la mejora de la empleabilidad y la reforma de las Políticas Activas de Empleo y el Real Decreto 1542/2011, de 31 de octubre. 
Por otro lado, la configuración institucional de este sector de política pública, en el que los gobiernos regionales poseen amplias capacidades de diseño y gestión de los programas, ha favorecido el planteamiento de vetos formales, dificultando la reforma de la gobernanza territorial de las PAMT en el sentido homogeneizador y centralizador pretendido por el Gobierno central. Un ejemplo concreto de ello lo tenemos en el caso del Acuerdo Marco de intermediación laboral de 2013. Los gobiernos regionales de Andalucía, País Vasco y Cataluña, en un primer momento, y posteriormente los de Baleares, Extremadura, Valencia y Castilla-La Mancha, se opusieron a suscribir el acuerdo alcanzado por el Gobierno central y las agencias de colocación alegando una invasión competencial por parte del SEPE. Con posterioridad el Juzgado Central de lo Contencioso-Administrativo determinó la anulación de la contratación de las agencias de colocación.

\section{Condicionantes supranacionales: la pertenencia a la UE}

Desde un punto de vista histórico-normativo, todos los entrevistados, tanto del nivel central de gobierno como los representantes regionales, coinciden en afirmar que el modelo de activación presente en España tiene una clara inspiración europea. Según el representante de una de las CC.AA seleccionadas «todas las políticas activas han sido en algún momento gestadas, creadas, evaluadas, dirigidas o copiadas de Europa». En el caso de la reforma de las PAMT, la pertenencia a la UE aparece como un factor explicativo clave, y no solo porque haya crecido la relevancia interna del FSE.

Así, las recomendaciones realizadas por el Consejo, que de manera reiterada insisten en la necesidad de reformar dichas políticas ${ }^{18}$, parecen estar detrás de una serie de planteamientos asumidos por el Gobierno central: la vinculación de la financiación a la consecución de resultados; el fortalecimiento de la focalización y la diversificación de los servicios y programas de activación para adaptarse a las necesidades de los desempleados; el desarrollo de un modelo organizativo basado en la noción de «ventanilla única», que elimine las duplicidades y facilite la accesibilidad a los programas y servicios de activación y, por último, la prestación de determinados servicios por parte de agencias privadas.

La UE sería un factor relevante, aunque ambivalente, en lo que respecta a la descentralizació/centralización de las políticas activas. Por un lado, a través del establecimiento de la regulación y los procedimientos en materia de empleo, la UE ha favorecido el desarrollo de normas por parte del Gobierno central que limitan el rango de flexibilidad decisional y financiera de las CC.AA. Pero, al mismo tiempo, el papel creciente de la UE en la financiación directa de las PAMT a través del FSE, y la flexibilidad asociada a la gestión de estos fondos, hace que los gobiernos regionales puedan experimentar con los programas y servicios de activación y tengan mayor margen de maniobra para adaptarlos a las peculiaridades de sus mercados de trabajo. Algunos estudios centrados en otros países de la UE como Alemania, que también cuentan con un Estado compuesto aunque con un régimen de bienestar y unas instituciones distintas, apuntan en esta dirección, señalando la influencia de la UE a través del FSE en los niveles subnacionales de gobierno (Stiller y van Gerven, 2012).

\section{CONCLUSIONES}

En este artículo se han analizado las reformas en materia de políticas activas del mercado de trabajo (PAMT) y su impacto en la organización territorial del Estado de Bienestar español en el periodo 2011-2016, enmarcado en la etapa conocida como Gran Recesión, la orientación de dichos cambios en relación al continuo descentralización /centralización y los factores explicativos de los mismos.

Desde un punto de vista teórico, el artículo ha aplicado los conocimientos de la literatura académica interesada en la organización territorial del Estado y su relación con el desarrollo de las políticas sociales, que integra líneas de investigación sobre descentralización y federalismo. Nuestro objetivo es contribuir a la literatura que trata la gobernanza de las políticas de activación en su dimensión territorial, centrada en los procesos de descentralización y los determinantes, tanto políticos como económicos, de la reforma territorial de los Estados de Bienestar.

Una primera conclusión del trabajo es que los cambios en la gobernanza territorial de las PAMT han seguido una orientación claramente centralizadora a partir de 2012, revirtiendo en cierta medida el proceso

18 Recomendaciones del Consejo relativas a los programas nacionales de reforma de España de los años $2011,2012,2013$ y 2014. 
descentralizador que había caracterizado a este sector de política pública desde mediados de la década de los 90. Las iniciativas desarrolladas por el Gobierno central a partir de 2012, centradas en la coordinación de las PAMT a través de indicadores de rendimiento específicos, el establecimiento de objetivos y principios de actuación comunes a todas las CC.AA, la regulación de la entrada del sector privado en la intermediación laboral, la segmentación y el carácter condicionado de una parte importante de los fondos estatales destinados a estas políticas, y el deber de proporcionar información periódica centralizada a través del SISPE, han incidido en la distribución de papeles entre los distintos niveles de gobierno, dando lugar a un proceso de centralización.

En este contexto, la situación económica adversa experimentada por el Estado Autonómico a raíz de la crisis financiera y fiscal iniciada en 2008-2009 sería uno de los factores explicativos del cambio en la gobernanza territorial de las PAMT y de la «vuelta» al liderazgo del Gobierno central, justificado por la necesidad de coordinar las políticas de consolidación fiscal, los objetivos de deuda de las CC.AA y la creación de empleo. Sin embargo, la crisis no sería la única variable explicativa de estos cambios. Las preferencias ideológicas, en este caso la concepción relativamente centralista del PP, en el Gobierno central desde 2012, un contexto político de claras mayorías tanto a nivel nacional como en los órganos intergubernamentales de decisión (que disminuye el riesgo de oposición por parte de las CC.AA y las necesidades de negociación con ellas), el rol de determinados actores dependientes del Gobierno central (en particular la DG del SEPE), o las recomendaciones realizadas por el Consejo Europeo, serían factores que también han contribuido a los cambios en la gobernanza territorial de las políticas objeto de nuestro análisis.

Aún así, las transformaciones experimentadas en las diferentes dimensiones de la gobernanza, aunque han alterado las pautas de relación entre los distintos niveles de gobierno, especialmente entre las CC.AA y el Gobierno central, han quedado en buena medida limitadas y han suscitado resistencias (con desigual intensidad) en diversas comunidades. Factores como la configuración institucional del sistema, que otorga a las CC.AA un considerable grado de autonomía decisional, administrativa y de gestión en materia de PAMT, o la ideología de los partidos que sustentan a los gobiernos regionales explicarían dicho fenómeno.

A la vista de las dificultades para medir los cambios en la gobernanza territorial de las políticas de activación y de las limitaciones presentes en la literatura académica en relación con los factores explicativos de los mismos, consideramos interesante seguir trabajando en la elaboración de un marco analítico más completo y detallado que permita profundizar en estas cuestiones.

No obstante, queremos resaltar que este proceso de centralización no se limita al sector de la activación. También es posible observar en otras políticas sociales, como la sanitaria o la de atención a la dependencia, tendencias de cambio similares, sin prejuicio de que existan diferencias en lo que atañe al alcance y los resultados de los procesos de reforma en cada una de las dimensiones estudiadas.

\section{REFERENCIAS BIBLIOGRÁFICAS}

BEACH, D. y PEDERSEN, R. B. (2013): Process-tracing methods: Foundations and guidelines. University of Michigan Press. BONOLI, G. (2010): "The political economy of active labor-market policy", Politics \& Society, 38 (4): $435-457$. DOI: $10.1177 / 0032329210381235$.

BORGHI, V. y VAN BERKEL R. (2007): "New modes of governance in Italy and the Netherlands. The case of activation policies", Public Administration, 85 (1): 83-101. DOI: 10.1111/j.1467-9299.2007.00635.x.

BRAUN, D. (2000): "Territorial division of power and public policy-making: An overview", en BRAUN, D., ed.: Public Policy and Federalism. Aldershot: Ashgate, págs. 1-26.

BRAUN, D. y TREIN, P. (2014): "Federal dynamics in times of economic and financial crisis", European Journal of Political Research, 53 (4): 803-821. DOI: 10.1111/1475-6765.12056.

CANAVIRE-BACARREZA, G. y MARTÍNEZ-VASQUEZ, J. (2012): "Fiscal Decentralization and Economic Crisis", en IEB Report on Fiscal Federalism Fiscal 2012. Barcelona. Institut d'Economia de Barcelona.

CHRISTIANSEN, P. M. and KLITGAARD, M. B. (2010): "Behind the veil of vagueness: success and failure in institutional reforms”, Journal of Public Policy, 30 (2): 183-200. DOI: 10.1017/s0143814x10000048. CLASEN, J., y CLEGG, D. (2011): Regulating the risk of unemployment: National adaptations to post-industrial labour markets in Europe. Oxford University Press.

DE LA PORTE, C. y HEINS, E. (2014): "A new era of European Integration? Governance of labour market and social policy since the sovereign debt crisis", Comparative European Politics. Nature Publishing Group, 13 (1): 8-28.

DE LA PORTE, C. y POCHET, P. (2012): "Why and how (still) study the Open Method of Co-ordination (OMC)?", Journal of European Social Policy, 22 (3): 336-349. 
DE LA PORTE, C. y WEISHAUPT, J. T. (2013): "The open method of co-ordination for social inclusion and social protection: Theoretical and empirical state-of-the-art.", en GARCÉS FERRER, J. y MONSONÍS PAYÁ, I., eds.: Sustainability and Transformation in European Social Policy. Bruselas: Peter Lang.

DE LA RICA, S. (2015): Políticas activas de empleo: una panorámica. Fedea Policy Papers, 1.

ELMELUND-PRÆSTEKÆER, C. y BAGGESEN KLITGAARD, M. (2012): "Policy or institution? The political choice of retrenchment strategy", Journal of European Public Policy, 19 (7): 1.089-1.107.

GRAZIANO P. R, JACQUOT, S. y PALIER, B. (2011): The EU and the Domestic Politics of Welfare State Reforms. Europa, Europae, Basingstoke, Palgrave Macmillan. DOI: 10.1057/9780230307629.

GRAZIANO, P. R. (2012): "Converging worlds of activation?", International Journal of Sociology and Social Policy, $32(5 / 6): 312-326$.

GRAZIANO, P. R., y RAUÉ, A. (2011): "The governance of activation policies in Italy: from centralized and hierarchical to a multi-level open system model?", en DE GRAAF, W., VAN BERKEL, R., y SIROVÁTKA, T., eds.: The governance of active welfare states in Europe: 110-131. Palgrave Macmillan UK.

GREER, S. L. (2010): "How Does Decentralisation Affect the Welfare State? Territorial Politics and the Welfare State in the UK and US", Journal of Social Policy. Cambridge University Press, 39 (2): 181-201.

GUILLÉN, A. M; GONZÁLEZ BEGEGA, S. y LUQUE BALBONA, D. (2016): "El Modelo social Europeo: Evolución y Retos", en DEL PINO, E. y RUBIO LARA, J. (eds.) Los Estados de Bienestar en la encrucijada: 80-199. Tecnos.

GUILLÉN, A. M. y PAVOLINI, E. (2015): "Welfare States Under Strain in Southern Europe: Overview of the Special Issue", European Journal of Social Security, 17 (2): 147-158. DOI: 10.1177/138826271501700201.

HACKER, J. S. y PIERSON, P. (2010): "Winner-take-all politics: public policy, political organization, and the precipitous rise of top incomes in the United States", Politics \& Society, 38 (2): 152-204. DOI: 10.1177/0032329210365042.

HEIDENREICH, M., y ZEITLIN, J. (eds.) (2009): Changing European employment and welfare regimes: The influence of the open method of coordination on national reforms. Routledge. DOI: 10.4324/9780203878873.

HOOGHE, L. y MARKS, G. (2001): Multi-level governance and European integration. Lanham: Rowman \& Littlefield Publishers.

HUMER, A., RAUHUT, D. y MARQUES DA COSTA, N. (2013): "European Types of Political and Territorial Organisation of Social Services of General Interest", Romanian Journal of Regional Science, 7: 142-164.

KAZEPOV, Y. (2010): Rescaling Social Policies: Towards Multilevel Governance in Europe. Surrey: Ashgate Publishing, Ltd.

KLITGAARD, M. B., SCHUMACHER, G. y SOENTKEN, M. (2015): "The partisan politics of institutional welfare state reform", Journal of European Public Policy. Routledge, 22 (7): 948-966. DOI: 10.1080/13501763.2014.978355.

LEÓN, M., PAVOLINI, E. y GUILLÉN, A. M. (2015): "Welfare Rescaling in Italy and Spain: Political Strategies to Deal with Harsh Austerity", European Journal of Social Security, 17 (2): 182-202. DOI: 10.1177/138826271501700203.

LÓPEZ SANTANA, M. y MOYER, R. (2012): "Decentralising the Active Welfare State: The Relevance of Intergovernmental Structures in Italy and Spain", Journal of Social Policy. Cambridge University Press, 41 (4): $769-$ 788. DOI: $10.1017 / \mathrm{s} 0047279412000335$.

LÓPEZ-SANTANA, M. (2006): "The domestic implications of European soft law: framing and transmitting change in employment policy”, Journal of European Public Policy, 13 (4): 481-499. DOI: 10.1080/13501760600693853.

- (2015): The new governance of welfare states in the United States and Europe: between decentralization and centralization in the activation era. Albany, NY: Suny Press.

- (2016): "Regional and Domestic Responses to the Unemployment Problem in Europe: Reconfiguring the Architectures of Welfare States", en BIANCULLI, A. C. y HOFFMANN, A. R. (eds.), Regional Organizations and Social Policy in Europe and Latin America. London: 117-138. Palgrave Macmillan UK. DOI: 10.1057/9781137490353_6.

MARTIN, J. P. (2014): Activation and active labour market policies in OECD countries: stylized facts and evidence on their effectiveness. DOI: 10.1186/s40173-015-0032-y.

MARTÍNEZ VALVERDE, J. F. (2014): El desarrollo autonómico y eficacia de las políticas activas de empleo: un análisis comparado. Madrid: Fundación Alternativas.

MATHIAS, J. (2017): Reforming the Swedish employment-related social security system: activation, administrative modernization and strengthening local autonomy. Regional \& Federal Studies, 27 (1): $23-39$. DOI: $10.1080 / 13597566.2016 .1255605$.

MINAS, R. (2011): "Decentralization and back to centralization: the Swedish case”, DOI: 10.1057/9780230306714_10, en DE GRAAF, W., VAN BERKEL, R. \& SIROVÁTKA, T., eds.: The governance of active welfare states in Europe. 195-215. DOI: 10.1057/9780230306714_10.

MOREIRA, A., ALONSO DOMínGUEZ, Á., ANTUNES, C., KARAMESSINI, M., RAITANO, M., y GLATZER, M. (2015): "Austerity-driven labour market reforms in southern Europe: Eroding the security of labour market insiders", European Journal of Social Security,17: 202-225. DOI: 10.1177/138826271501700204.

MORENO, L. y SERRANO-PASCUAL, A. (2007): "Europeización del Bienestar y Activación”, Política y Sociedad, 44 (2): 31-44.

- (2011): "Europeanization and Spanish Welfare: The Case of Employment Policy" en GUILLEN, A. M. y LEÓN, M. (eds.): The Spanish Welfare States in European Context. España: 39-58. Ashgate. 
MURO, D. (2009): "Territorial accommodation, party politics, and statute reform in Spain". South European Society \& Politics, 14 (4): 453-468. DOI: 10.1080/13608740903503845.

NEGUERUELA, E. (2015): Agencias privadas de colocación: sancionadores a comisión, Nueva Tribuna. Disponible en: http://www.nuevatribuna.es/articulo/economia-social/agencias-privadas-colocacion-sancionadores comision/20151202081710122962.html (accedido: 7 de enero de 2017).

OECD (2003): Managing Decentralisation: A New Role for Labour Market Policy, Paris, OECD Publications.

OECD (2013): The 2012 labour market reform in Spain: a preliminary assessment. DOI: 10.1787/9789264213586-en.

PAVOLINI, E. y DEL PINO, E. (2015): "Decentralisation at a Time of Harsh Austerity: Multilevel Governance and the Welfare State in Spain and Italy Facing the Crisis", European Journal of Social, 17 (2): 246-271. DOI: $10.1177 / 138826271501700206$.

PIERSON, P. (2001): "Coping With Permanent Austerity Welfare State Restructuring in Affluent Democracies" en PIERSON, P., ed.: The New Politics of the Welfare State, 410-456. Oxford: Oxford University Press. DOI: 10.1093/0198297564.003.0014.

SMISMANS, S. (2004): Law, Legitimacy and European Governance: Functional Participation in Social Regulation. Oxford: Oxford University Press.

- (2006): "New Modes of Governance and the Participatory Myth", European Governance Papers (EUROGOV), núm. N-06-01, <http://www.connex-network,org/eurogov/ pdf/egp-newgov-N-06-01.pdf>.

STARKE, P., KAASCH, A. y VAN HOOREN, F. (2014): "Political Parties and Social Policy Responses to Global Economic Crises: Constrained Partisanship in Mature Welfare States”, Journal of Social Policy, 43 (2): $225-246$. DOI: $10.1017 / \mathrm{s} 0047279413000986$.

STILLER, S. y VAN GERVEN, M. (2012): "The European Employment Strategy and national core executives: impacts on activation reforms in the Netherlands and Germany", Journal of European Public Policy, 22 (2): 118-32. DOI: $10.1177 / 0958928711433652$.

TREIN, P. y RUIZ, C. (2015): "Fiscal Centralization in Times of Crisis: Evidence from 11 Federal States", Electronic Journal.

VALVERDE, J. F. M. (2014): El desarrollo autonómico y eficacia de las políticas activas de empleo: un análisis comparado. Fundación Alternativas.

VAN BERKEL, R., DE GRAAF, W.y SIROVÁTKA, T. (eds.) (2011): The governance of active welfare states in Europe. Springer. DOI: 10.1057/9780230306714_1.

VERSCHRAEGEN, G., VANHERCKE, B., y VERPOORTEN, R. (2011): "The European Social Fund and domestic activation policies: Europeanization mechanisms", Journal of European Social Policy, 21 (1): 55-72. DOI: $10.1177 / 0958928710385733$.

VIEBROCK, E. y CLASEN, J. (2008): "Flexicurity and welfare reform: a review", Socio-Economic Review, 7 (2): $305-331$.

WEISHAUPT, J. T. (2010): "A silent revolution? New management ideas and the reinvention of European public employment services", Socio-Economic Review. 8 (3): 461-486.

\section{NOTA METODOLÓGICA}

El trabajo empírico realizado ha recurrido al análisis de datos tanto secundarios como primarios y se ha basado en el empleo de técnicas de investigación cualitativas.

Junto a la revisión de la bibliografía especializada se ha procedido al análisis de una variedad de documentos que incluye notas de prensa de los responsables públicos del sector del mercado de trabajo en los diferentes niveles de gobierno, textos legales e informes emitidos por organizaciones internacionales y actores sociales.

Asimismo se han realizado y analizado 15 entrevistas semiestructuradas. Dichas entrevistas tuvieron lugar en el periodo comprendido entre mayo de 2016 y marzo de 2017, en el marco de un proyecto de investigación más amplio. A tal fin se procedió a la elaboración de un guión de temas que abordaba los cambios en la gobernanza territorial de las PAMT desde una triple perspectiva: los procesos de adopción de decisiones en relación con el diseño de la política, la implementación de las iniciativas de activación y la financiación de las mismas. El guión también incluía cuestiones referidas a la influencia de diferentes factores socioeconómicos, políticos e institucionales sobre dichos cambios, su contenido, alcance e implicaciones en términos del peso relativo de los distintos actores implicados en la política.

Los criterios de selección de los actores/informantes entrevistados han sido, fundamentalmente, dos: en primer lugar, el nivel territorial (CC.AA o nivel central de gobierno); en segundo lugar, el perfil del entrevistado (por un lado su carácter predominantemente político o técnico, por otro su actividad en el ámbito específico de las políticas de empleo -SEPE y SEPR- o en departamentos de carácter más «horizontal»-Economía y/o Hacienda-). 
Nuestra unidad de observación han sido las PAMT (programas y servicios) y las CC.AA nuestras unidades de análisis. Concretamente hemos seleccionado tres comunidades: Castilla-La Mancha, Madrid y Comunidad Valenciana. En un intento de relacionar los objetivos de la investigación con una coherente selección de casos, hemos optado por la estrategia de comparar sistemas similares (Przeworski y Teune, 1970). En primer lugar, las tres CC.AA han experimentado un contexto económico de deterioro de su situación fiscal, afectadas por la crisis de la deuda y las restricciones presupuestarias, y sus gobiernos autonómicos se han visto obligados a diseñar medidas de austeridad sin precedentes. En segundo lugar, se trata de regiones que comparten características institucionales básicas y similares grados de autonomía política y financiera. Por último, desde el punto de vista del color político de los gobiernos, y para el periodo de análisis, difieren en el partido que sustenta a sus ejecutivos: dos de ellas están gobernadas por el PP y una por el PSOE. 